\title{
Revisiting the history, concepts \& typologies of community management for rural drinking water supply in India
}

\begin{abstract}
Community management has been widely criticised yet it continues to play a significant role in rural drinking water supply. In India, as with other 'emerging' economies, the management model must now adapt to meet the policy demand for ever-increasing technical sophistication. Given this context, the paper reviews the history and concepts of community management to propose three typologies that better account for the changing role of the community and external support entities found in successful cases. The paper argues that external support entities must be prepared to take greater responsibility for providing on-going support to communities for ensuring continuous service delivery.
\end{abstract}

Keywords: Community management; rural water supply; participation; service delivery; India

\section{Introduction}

As India undergoes rapid economic growth, the Government of India aims to significantly improve its public service delivery. This is reflected in its ambitions to "ensure at least $80 \%$ of rural households have piped water supply with a household tap connection" by 2022 (MDWS, 2013, p. 2). With 31\% of households enjoying a piped connection in 2011 (Census of India, 2011), meeting this ambition will involve serving an additional 400 million people with household connections in little over a decade. This represents an important policy shift in rural drinking water supply, moving from an emphasis on expanding access, usually through handpumps, to an approach based on improving service levels, through piped schemes. Change at this pace and scale poses significant challenges to the viability of the community management model for rural drinking water supply in India. Analysis of rural water supplies in India reports levels of over 30\% of 'slippage' (Government of India, 2009), defined as the percentage of villages that once had achieved full coverage and that are now back to partial coverage, 
either because existing systems failed or because villages have grown and system capacity has not kept pace with that growth. With 'community management' a declared part of many government supported programmes, this type of poor performance, not only in India but in many parts of the developing world, is leading to suggestions that community management has reached its limits (Harvey \& Reed, 2006; Moriarty, Smits, Butterworth, \& Franceys, 2013). It is now accepted that communities cannot independently operate and maintain drinking water supply systems, even with relatively low complexity installations (Baumann, 2006; Lockwood \& Smits, 2011; Moriarty et al., 2013; Schouten \& Moriarty, 2003).

Yet for too long the assumption that consumers can run their own water supply has led to situations of "communities unable to cope with management of their schemes, poor maintenance, lack of financing, breakdowns, poor water quality, lack of support and, ultimately, an unreliable and disrupted supply of water to households" (Lockwood \& Smits, 2011, p. 1). In the context of the move to piped water supply, it is necessary to reconsider what is a 'good enough' level of community management and what level of support communities need to avoid slippage. In response to these issues, the paper, based on the authors' academic research as well as multi-year experience in programmes seeking to deliver sustainable rural water supply, aims to provide a realistic conceptual model for community management that emphasises the importance of factors beyond the community, namely on-going government (or other entity) support services. To achieve the stated aim, first, the paper provides an overview of community management in India describing the history of the model within the country. Second, the paper describes the emergence of community management within the international context. Third, based on these discussions, three different modes of community 
management are proposed that better account for the differing intensities of external support and community involvement that fall under the present community management label. Fourth, a literature review is used to map current practice against the proposed model. The paper concludes by reflecting on the role of external support - usually from the government - in all successful forms of community management.

\section{Community management for rural water supplies in India}

India has a long history of community management. Early experiments were tried as far back as 1964, with the World Health Organisation and UNICEF Banki and Mohkampur projects in Uttar Pradesh running with some limited success until 1994 and 1976 respectively, and the sister Pharenda project reported as still ongoing at the time of the last citation (WSP, 2002). Tracing the genealogy of community management from these early initiatives to the present day, this section begins by drawing on James' $(2004,2011)$ synthesis reports to identify four broad categories of community management initiatives. These include independent cases where communities have simply taken complete charge of water supply when government services have failed, small scale NGO initiatives, larger scale donor-NGO schemes support by bilateral and multilateral agencies, and then the post-Sector Reform government-supported programmes that emerged from 1999 onwards. The learnings from each category will be briefly discussed in order to demonstrate how community management has changed throughout this period.

With the provision of safe drinking water constitutionally mandated as the government's responsibility it is rare for communities to be completely autonomous in the management of drinking water. However, there are limited cases of reportedly independent piped schemes such as the case in Kolhapur (Maharashtra) that ran from 1979 until the 1990s (James, 2004). This occurred after the District Administration 
refused to take on a government-constructed piped water network so taking their own initiative community members from four villages came together to form an unofficial committee that took responsibility for the piped network. Without any further support they managed the scheme for 20 years, even creating a big surplus in the committee's accounts (James, 2004). Whilst this case of unsupported community managed piped water supply is relatively rare, it does demonstrate that it is possible. Yet its eventual failure also highlights how "even a successful community management initiative requires a support structure to cope with external shocks and stresses” (James, 2004, p. 39).

As opposed to the paucity of completely independent cases, there have been many small-scale $N G O$ projects that have been significant in developing the contemporary practices of community management in India. As James (2004) illustrates with a number of examples, including: the Utthan programme from Gujarat, started in 1981, which demonstrated the influential role of women as 'spearheads' of community water supply campaigns; Self-Employed Women Association's experience, also in Gujarat from 1972, that illustrated the need for capacity building of women's groups if they are to be successful spearheads; the work of the Watershed Organisation Trust in Maharashtra and Karnataka from 1996 emphasising the importance of trust between support entities and service providers as a basis for successful community management; and Gram Vikas, whose work began on water supply in 1981 in Odisha, who pioneered an intensive participatory approach based on the equitable principles that including 'every household' is the key to sustainable outcomes. These examples merely touch the surface of the numerous NGO programmes operating over the past decades yet they serve to demonstrate the importance of NGOs in the establishment of community management. But arriving at such outcomes involved time consuming "trial and error- 
based experimental" approaches that were often costly in terms of resources and which require specialist skill sets (James, 2004, p. 49). This makes this kind of approach only limitedly scalable - as such resources and skills sets are often not available, and cannot easily be employed in programmes that cover many villages.

Throughout the 1990s and the early 2000s, the (supposedly) demand-responsive approach to community management was introduced to the country through a number of bilateral and multilateral donor-NGO programmes (Black \& Talbot, 2004). The demand-responsive approach was based on the principles that users should express their demand through what they are willing to pay, and based on that the appropriate level of technology is put in place (Isham \& Kahkonen, 2002). This usually was based on the notion that communities contribute $10 \%$ of capital costs and then cover operation and maintenance through tariffs. However, in India as elsewhere, the demand-responsive approach has been implemented only to a limited extent. The $10 \%$ upfront contribution - through which users are supposed to express their demand - is waived in many cases or - as much anecdotal evidence suggests - paid for by contractors, so they can get on with the work. The $100 \%$ cost recovery principle has also not been applied systematically. The myriad of direct payment of water related costs by public bodies, such as the energy costs for pumping, the costs of water quality testing and major repairs, means that actually only a small part of the costs have to be paid by users: minor repairs and maintenance and some of the operating costs, like salaries of pump operators. Notwithstanding these limitations, the concept of the demand-responsive approach has been extremely widespread in internationally supported programmes with examples including the KFW (German Development Bank) funded Aapni Yojna Project in Rajasthan (1994-2004), World Bank programmes in Maharashtra and Karnataka 
(1991-2000), and the World Bank Swajal Project in Uttar Pradesh (1990s). As opposed to the smaller-scale NGO approaches, these initiatives had budgets between $\$ 60-100$ million and sought to serve a larger number of villages (500-1000), often making use of smaller NGOs as partners (James, 2004). Professional approaches to community management were developed in this period, including building participatory methods into the design stage of programmes, scheduled training schemes with community members to build capacity, and tripartite agreements between Village Water and Sanitation Committees (VWSC), support organisations and overall programme managers. However, despite professional practice, government requirements in areas such as procurement prevented community management flourishing beyond these programmes as community entities were unable to make use of allocated government funds or access government procurement processes (James, 2004, 2011). A new form of government-supported community management emerged from 1999 onwards. In that year, the Government of India implemented Sector Reform Pilot Projects (SRPP) in 67 districts across 26 states and so began the process of integrating community management into its national policy. In many states, new institutions were formed, including District level Water and Sanitation Committees, which received funds directly from the Union Government bypassing state level agencies. Whilst there was some success in the pilot programmes, there was also resistance to change from officials who were used to a supply driven model and inadequate support at state and district level "to provide backstopping and trouble-shooting" when initiatives failed (James, 2004, p. 39). Despite these flaws, in 2002, the Government of India launched the Swajaldhara programme. The Swajaldhara programme advocates community management along the following principles: a demand-driven approach; village level capacity building for community management through VWSCs; an integrated service 
delivery mechanisms that streamlined the functioning of the government agencies involved; demand-responsive approach based cost-sharing by users ( $100 \%$ of operation and maintenance costs; $10 \%$ of capital costs); and, water conservation measures through rainwater harvesting and groundwater recharge measures (Government of India, 2003). In practice it is questionable whether these claims were met even in successful schemes, as the Swajaldhara claim of $100 \%$ operation and maintenance covered by the community does not reflect the many indirect (and hidden) subsidies in India that support rural drinking water supply, including electricity subsidy and administrative support to VWSC through the local government system. There are also cases when the programme has been poorly implemented, such as the one highlighted by Srivastava (2012), where the Swajaldhara programme in one area merely became a sham with no community management but water supply run by local elites for their own benefit. The sheer scale of the reform meant institutions at many levels did not have the capacity to implement the aspirational objectives and the Swajaldhara programme "had roughly the same impact on sustainability as the regular...supply-driven model followed in the country since $1972-1973 \ldots$. largely because of the inadequate preparation and capacity building - especially among the engineers as well as the community and NGOs" (James, 2011, p. 54). Notwithstanding the criticism, Swajaldhara was still significant as it legalised community management within the prevailing governance model, providing a formally recognised legal basis for communities to become service providers and thus removed barriers regarding their access to government funds and procurement procedures. Perhaps most significantly the Swajaldhara provided an impetus for a number of highly successful state-based programmes to flourish in the last decade including the Water and Sanitation Management Organisation(WASMO) in Gujarat, Jal 
Nirmal in Karnataka, Jalanidhi in Kerala and Jalswarajya in Maharashtra (James, 2011; Lockwood and Smits, 2011).

Following Swajaldhara India is now home to a rich diversity of community management experiences. However the latest policy programme from the Government of India has sought to further formalise the model within the broader system of local self-government. Launched in 2009, the National Rural Drinking Water Programme (NRDWP) the successor to Swajaldhara has consolidated the importance of the Gram Panchayat institution in rural water supply with greater responsibility and funds devolved to this level. With the Gram Panchayat being the lowest level of government in the Panchayat Raj system of government that operates in rural India. These bodies have an elected President covering a 'village' (though typically each village covers a number of habitations) and are responsible for many public services, including domestic water supply. However, under these guidelines, a VWSC is still formed however it operates as a sub-committee of the local self-government (Government of India, 2012). These nominated committees have between 6 and 12 members including the President of the Gram Panchayat and with a quota of at least $50 \%$ representation of women, and are charged with the administration, operation and minor maintenance of rural water supply. However, the close institutional relationship with the Gram Panchayat means the VWSC is far from autonomous. Experience from the field indicates that this has often lead to dual systems developing whereby in certain villages the Gram Panchayat simply becomes the direct service provider whilst in other villages the VWSC are formed to enact community management with support from the Panchayat institutions (Rout, 2014). In many ways, the NRDWP promotes an institutional structure that is both robust and admirably malleable in that various institutional variations can emerge, even within the same programme. Yet this can also mean a lack of clarity over the exact 
nature of institutional arrangements, leading to questions over who takes key roles such as service provision or service monitoring. Furthermore, the diversity of approaches to rural drinking water supply is likely to grow further as the NRDWP comes to the end of its 5 year cycle and the Government of India has abandoned its Planning Commission replacing it with the NITI Aayog (National Institutions for Transforming India) which has less direct power over policy and, hence, in the long term this move is likely to mean more freedom for States governments to promote different models for rural drinking water supply (Government of India, 2015). Together, this historic review shows that there are many different types of community management and current policy trends are likely to lead to even greater diversity in practice. Yet the range of models and changes in the policy landscape now mean there are tensions - or at least conceptual uncertainties - with regards to the role of communities vis-à-vis the state. It is contended that this ambiguity is poorly reflected in the discourse of community management that tends to characterise it as one identifiable approach when in reality the label is used to describe many different institutional arrangements. Through better differentiation it is felt that the more appropriate forms of support can be tailored to specific forms of community management.

\section{Differentiating types of community management for rural water supply}

The theoretical foundations for community management of rural water supplies lie in the broader work on community participation in (rural) development so this section takes a look at the early literature associated with participation in the rural water sector. For this purpose, we expand the analysis to focus on the international context as it is in this literature that the links between the broader movement of community participation in development and the community turn in rural drinking water supply is most explicit. In the 1980s multilateral donors and other development stakeholders began to adopt the 
principles of community participation in development projects. In an early definition, the World Bank defined it as: "an active process whereby beneficiaries influence the direction and execution of development projects rather than merely receive a share of project benefits" (Paul, 1987). In this sense, the objectives of community participation were often conceptualised in a technocratic manner, with an emphasis on issues such as sharing project costs, increasing efficiency and efficiency (McCommon, Warner, \& Yohalem, 1990). In rural drinking water supply this thinking became manifested through the 'VLOM' approach (Village Level Operation and Maintenance), which advocated communities taking full responsibility for operation and maintenance of basic technologies and systems. It was building on what had earlier been called the 'appropriate technology' movement that favoured low-cost technology purposefully designed to require minimal external inputs in development projects (Colin, 1999). In the water sector, this primarily referred to handpumps. Yet, in practice, many communities were ill-prepared to take on the required management responsibilities, even of the most low-cost technologies. The often forgotten aspect of the previous 'appropriate technology' paradigm was the requirement for renewal and rehabilitation through access to capital maintenance funds. Many VLOM programmes were also advocated by external agencies that favoured working directly with communities and grassroots organisations, thereby by-passing government structures, which in turn meant that after these programmes ended communities were left completely alone to manage their systems.

By the end of the 1990s the international discourse of community management developed further, putting increasing emphasis on participation within the demandresponsive approach. As we alluded to in the previous section, the demand-responsive approach approach had a number of limitations. First, communities should express 
demand for services, which was expected to be manifested most obviously through user contributions to capital costs. That - so the argument went - would lead to a sense of ownership and hence commitment to ensuring on-going operations and use. Whilst there is some evidence this approach led to success (Whittington et al., 2009), real ownership of assets, in legal terms, often remained vaguely defined (Black \& Talbot, 2004) whilst Marks and Davis (2012) show that the level of contribution required needed to be significantly high to create such a sense of ownership. Second, full cost recovery was the ambition, understood to refer to user tariffs covering all operation and minor maintenance costs - which of course were only a subset of the full costs - but in practice it often has taken a long time for communities to mobilize such contributions and where they were made, they were often minimal (Jones, 2013). Third, more meaningful participation in decision-making was sought. In order to achieve the previous two points, many organisations (particularly NGOs) emphasised the importance of participation in projects. The idea was to give a stronger voice to communities in expressing demand and decision-making in, for example, technology selection, tariff setting, establishing the management model and preparing them better for their role in eventually managing the service. In this period, a range of participatory methodologies and tools were developed and specified for rural water supplies (Bolt \& Fonseca, 2001; Dayal, Wijk-Sijbesma, \& Mukherjee, 2000; Deverill, Bibby, Wedgwood, \& Smout, 2002; Lammerink \& de Jong, 1999), often becoming part of the standard intervention model for implementing organisations.

Building on these ideas, and our analysis of global rural water supply (Hutchings et al., 2015) and our desk-based analysis of 'successful' rural water supply programmes in India (see below), we develop three typologies of community management, with different levels of balance between what communities themselves do, and the extent to 
which they are supported by external agencies. They include: 1) direct provision with community involvement, 2) community management plus and 3) professional community-based management. These categories have also been used in a recent systematic review of the global evidence on the success factors for community management over the past 30 years (Hutchings et al., 2015). However, this paper is intended to provide a more thorough justification of these categorisations based on a review of the history and theory of community management in India. Beyond these categories, we recognise that there is also the possibility of community management without any support but this is not considered a scalable model so is excluded. It is also acknowledged that there are other options for rural drinking water supply, such as selfsupply or direct public provision with no community role but these are not considered here either.

The theory underlying the typologies is that the type of community management is dependent on contextual factors particularly the cost of supply and the communities' ability and willingness to contribute to these costs (i.e. the demand). It is recognised that these are in turn driven by many other factors such as hydro-geological conditions and the development status and context of villages. Figure 1 reflects this thinking with respect to the spectrum of likely costs of supplying households with water relative to their ability and willingness to pay, with an attempt to segment the different consumer groups relative to these factors. This thinking recognises an 'economic provision efficiency frontier' within the model that dictates the crude divisions between the community management typologies. Classically, an economic efficiency frontier is described with a curve (rather than Figure 1's 'steps') whereby any service provider on that curve is equally efficient in maximising outputs relative to inputs, even when using different patterns of inputs and outputs. In this example the emphasis is on different 
contexts of inputs that affect the costs of supply and the community's ability to contribute, whether housing density, consumer wealth or hydrogeology, with these linking to different likely forms of service delivery. Figure 1 therefore represents the potential of delivering differentiated services across such contexts supported by appropriate resource contributions from the community (tariffs and/or volunteer involvement) at an appropriate and efficient level. The line representing 'the universal service obligation', the requirement for a service provider to deliver a common basic service at a standard price (an idea derived from the postal and telephone sectors), suggests that for the very poor and even for some higher-income groups in low-density, high supply cost areas, there will be a need for the state to take responsibility for 'uneconomic' direct provision. This is still seen as benefitting from involving communities to every extent possible to deliver ongoing effectiveness and equity but equally recognises that communities will be unable to take the lead in very remote, very poor, very hydro-geologically-challenged or very low population density areas. The distinction between the 'universal service obligation' frontier and 'universal ('100\%') service' acknowledges that there will be a percentage, increasingly small it is hoped, who are beyond the reach of formal water services.

Figure 1: Typologies of Community Management in relation to demand and costs of water supplies. Source: adapted from Franceys and Gerlach (2008) after Stern et al. (2007)

Across this demand and supply continuum we understand that it is entirely reasonable that the intensity of community participation will vary. Whilst developing the evidence base further in our ongoing research we posit that it is likely to follow something like a normal distribution curve across income groups. Communities with higher incomes are likely to contribute principally through tariffs, with these funds used to professionalise 
the service with paid-for staff, and through involvement at committee/board or consumer involvement level in what can be called a Professionalised Community-Based Management model. Those communities dominated by people with very low incomes and fragile livelihoods are likely to have little additional capacity to contribute to managing the water system, so will require a form of direct provision with ideally some community involvement over key decisions but not necessarily involvement with operation and maintenance. In the middle, 'community management plus', communities are more likely to provide volunteers to take on key duties related to operation, maintenance and administration whilst providing modest cost contributions via user charges. Below, we examine each typology in more detail and describe how these function in India but when reading these descriptions readers are encouraged to recognise them as on a broad continuum of community management with an intentional degree of overlap across the typologies.

\section{Direct provision with community involvement}

Communities with limited socio-economic capacity and in more difficult to serve areas are most likely to require direct provision with only limited community involvement. In other cases the requirement for high-level water supply technology, such as reverse osmosis treatment plants in quality affected areas, can mean the technical demands of managing the system are so high that direct provision is the most appropriate approach even for communities with medium to high level capacity. Direct provision with community involvement is a model of service delivery whereby an external provider manages the water system, including the major tasks of operation, maintenance and administration, as well as overseeing the initial infrastructure development and investment cycle. The external provider is also likely to retain ownership of the infrastructure assets. This body then carries out activities directly or outsources them to 
other local partners, such as contracting work to small private operators to carry out borehole drilling. The external provider is also expected to provide appropriate capacity development activities, such as training, for any tasks expected by the community. In India, this external provider may be the district level office of the Public Health Engineering Department or affiliated government body, although rarely it could also be a NGO or subsidised social enterprise. The external provider can also be the Gram Panchayat Institution that fulfils service provider functions.

However, even in such cases it is appropriate to involve community members in discussions about the selection and implementation of new technical solutions. Ideally there will also be some form of village water committee instituted but to act more as a channel for communications and consultation rather than management. The water committee will then be expected to perform limited day-to-day duties such as keeping water points clean and simple preventative maintenance. Under the Gram Panchayat model, formal community involvement is organised through the Village Water and Sanitation Committees however the degree of community participation is low, as the committee has limited power and capacity, yet it is appropriate for the context. Typically, the models of Direct Provision with Community Involvement are more likely to be found in the poorer states especially in large-government supported programmes. For example, in Jharkhand, the Drinking Water Supply Department delivers water supply to communities through a variety of programmes including the NRDWP and Swajaldhara (DWSD-GoJ, 2015). As part of these programmes, communities can form committees to take on responsibility for service provision. However, the bulk of activities and resource inputs are provided by either the DWSD or the Gram Panchayats. 


\section{Community management Plus}

Rural communities in the middle part of the curve presented in Figure 1 are perceived to be served by community management plus - or what may be considered the 'classic' form of the model with high levels of voluntary participation from the community and some degree of direct support. This approach is particularly common with systems at the simpler end of the technical spectrum, such as borehole hand-pump schemes, simple gravity flow and powered pump systems without a distribution network, where more of the management aspects of the system are believed to be within the capability of community institutions. Community involvement is likely to be organised through a community-based organisation, typically an elected water committee that is actively encouraged and supported by the external provider. At the initial stages of development of the water system, the voluntary committee will be formed to take decisions on technology choice, user charges and the code-of-conduct for water supply in the community. On an on-going basis, the water committee will be expected to perform day-to-day duties such as keeping water points clean and preventative maintenance and providing fuel where pumps are motorised without an electricity connection. They will also be responsible for calling down the external provider for major operation and maintenance activities. Community contribution via user charges might be expected, although it would be unable to meet all the costs of running the system and significant external subsidy is still required.

When functioning at a high level the community-based organisation may also subcontract some of these tasks to an individual (plumber, handpump mechanic or technician). Whereas studies show that communities can and do fulfil many of the provider functions (Bakalian \& Wakeman, 2009; Harvey \& Reed, 2006; Schouten \& Moriarty, 2003), many communities struggle with sustaining their water supplies, with 
some succeeding and others failing, giving rise to the notion of 'islands of success' (Davis \& Iyer, 2002). This has not so much lead to the conclusion that the classic form of community management does not work, but rather that it has its limitations and that communities on their own may not be able to. As such, from the early 2000 s, recognition grew that rural communities require some form of on-going external monitoring and support in service delivery (Lockwood, 2002; Schouten \& Moriarty, 2003), and that indeed such support must be seen as integral to community management (Lockwood \& Smits, 2011). For us, this kind of monitoring and support includes some forms of direct support in this type of community management, such as in technical monitoring and backstopping.

In India, Gujarat provides the most widely celebrated example of community management plus. WASMO, the special purpose public body formed in 2002, operates as a facilitating organisation that encourages communities to manage their own drinking water supply systems and services (James, 2011). WASMO encourages the creation of village-level institutions to take on the role of service providers but focuses on information, education and communication (IEC) activities to continuously build capacity at the village level. There are also a number of technical public departments that can provide specialist hardware support when needed, particularly the implementation of bulk water schemes. WASMO has served over 18,000 villages through this model.

\section{Professionalised community-based management}

Professionalised community-based management is characterised by a move away from an approach based purely on volunteerism, towards a more professional, competent and effective management of rural water services working to agreed standards and with greater transparency and accountability (Lockwood \& Le Gouais, 2011; Moriarty et al., 
2013). This is the 'utilitisation' of rural water services by one description and instead of the term community service provider, the term 'operator' can be used, reflecting the terminology of the urban water sector. Professionalisation may take three major forms: 1) The adoption of good business practices, such as billing, book keeping and auditing, systematic carrying out operation and maintenance tasks, managing customer relations etc.; 2) The contracting of paid-for staff, such as plumbers or an administrator to carry out the different functions as a dedicated task. In larger and more complex systems, such as multi-village schemes serving rural growth centres, community-based organisations may fully contract out all these operational functions; 3) Calling down professional support. This refers to cases where the community-based organisation proactively seeks and obtains support from a professional support agent. It requires professionalism of the community-based organisations to recognise its limitations and the willingness to contract specialised support. It is likely in this model that all operations and minor maintenance costs are recovered through user charges though major renewal capital maintenance costs will need to be supported externally. The professionalised community-based management may evolve eventually into something even closer to a conventional utility model, whereby none of the service provider tasks are carried out by a community-based organisation. The community should still be engaged, however, in certain monitoring and customer involvement functions - a model more common in urban areas. It is important to note that the difference with the previous type of community-management plus is a gradual one. Support organisations may gradually take on more and more monitoring tasks, and push a community-based organisation to operate more professionally. In India, evidence of a professional community-based management approach can be found in Kerala where communities have been supported to form independent 
committees who operate as professional organisations running multi-village schemes. Kerala has larger Gram Panchayats and so this may lend itself toward more professional models of management covering up to 50,000 people compared to 5,000 in the rest of India. In Nemeni Gram Panchayat, Wayanad, the Jalanidhi programme was introduced to promote community management in 2005 . This lead to the formation of a Scheme Level Executive Committee that took on responsibility for 52 small scale water distribution systems serving a population of over 40,000 people. Working with local government, NGOs and private contractors, the community-based Scheme Level Executive Committee raised money for the implementation of the Nenmeni rural drinking water supplyScheme to provide household supply to many people in the village. It now operates and maintains this system collecting tariffs to cover much of the costs.

\section{A unifying feature - the Enabling Support Environment}

Key to all the models discussed is the presence of what is called in the Indian context an 'Enabling Support Environment' that is made up of various support entities that fulfil what Lockwood and Smits (2011) classify as service authority functions. The rationale for viewing the authority functions as separate from the community provider functions comes from the idea that one needs to separate the direct provider role from the support and monitoring role. At this supporting level various functions must be completed including planning, coordination, regulation, monitoring and oversight, and direct support functions, such as funding and technical assistance. All these functions can be fulfilled by a single entity, such as a Public Health Engineer Department, but often they are spread over different organisations, including the Gram Panchayat. Even though variations on this ideal exist, the support entity is also typically the legal owner of assets even when the assets were fully developed by a community itself through a self-supply 
approach. In the Indian context, the formal ownership of assets usually sits with the government, through the Gram Panchayats, even when a distinct community group develops these assets. In such a role, the support entity therefore formally delegates the service delivery role to a designated provider, for example in the form of contract, agreement or otherwise. However, in many cases community-based organisations operate only de facto as provider, lacking the formal mandate or delegation from the respective authorities. They only have a "sense of being a service provider" but have not the formal function of "service provider" (Lockwood \& Smits, 2011, p. 76). In some cases, the authority also assumes some of the service provision tasks, for example carrying out repairs over and above a certain magnitude. That in itself is not a bad situation, as long as it is clear who is responsible for what services. Unfortunately, in many cases the responsibilities for certain functions are not defined at all, or left ambiguous, leading to poor outcomes. For example, wrongly assuming that communities have the responsibility and resources to manage capital maintenance is likely to lead to higher 'slippage.'

For the direct support functions, various authors use different terminology: institutional support mechanisms (Lockwood, 2002), follow-up support (Lockwood, Bakalian, \& Wakeman, 2003), post-construction support (Bakalian \& Wakeman, 2009), direct support (Smits, Verhoeven, Moriarty, Fonseca, \& Lockwood, 2011) and support to service providers (Smits, Rojas, \& Tamayo, 2013). We adopt the term 'service delivery support' - referring to support throughout the service delivery cycle from project implementation through ongoing service delivery to renewal and expansion - that is the 'plus' of what this research refers to as 'Community Water Plus' (adapting Baumann's (2006) Community Management Plus terminology). The main objective of such support is to help communities in addressing issues they cannot reasonably solve on their own 
and gradually improve their performance in their service provider functions. Smits et al. (2011) building on Whittington (2009) identify the following typical support activities: Monitoring, including water quality testing and auditing; Technical advice in aspects of operation and maintenance, administration and organisational development; Conflict resolution and moderating between different groups in the community; Support in identifying capital maintenance needs and resource mobilisation, financial and technical, for such works. Monetary or material support is ideally not considered part of the support functions but in reality is often required. Support may also include (re)training and refresher courses for service providers or provision of information materials, such as manuals, guidelines and other information material. Whilst different forms of support are needed across contexts, in large scale programmes we believe that support networks must be able to fulfil the required support roles across any of the three proposed typologies depending on the circumstances of a particular village or group of villages.

\section{The presence of the different typologies of community management across India}

This penultimate section attempts to assess how current practices in India map against the typologies described in the previous section. Based on an extensive review of grey and academic literature, as well as two expert stakeholder consultation meetings held in Hyderabad and Delhi during August and September 2013, respectively, we identified a sample of over 90 programmes that followed a community management approach and that were reported as successful (see Supplementary Information A1), in the sense that the water supplies managed by these communities were generally providing adequate services with a meaningful role for communities. Based on the scale of operations described in the respective reports, we can estimate that these programmes cover 31,693 
villages out of an all India total of 597,483 villages (Government of India, 2011).

Taking the average population size per village of 1,395 people, this suggests that at least approximately $44,211,735$ out of the $833,463,448$ rural population, or over $5 \%$, are receiving reportedly successful community managed rural water services. It is expected that there are many additional cases that are not reported in the literature and therefore in that sample. However, this initial analysis still indicates that community management represents a viable model for a significant minority of people but that the majority of villages in India are not following a successful community management model, because either community management is not successful or other management models are followed.

As suggested earlier in the paper, four large State programmes account for $88 \%$ of the habitations in this sample (see: Table 1). They include WASMO in Gujarat, Jal Nirmal in Karnataka, Jalanidhi in Kerala and Jalswarajya in Maharashtra. These programmes demonstrate that large scale community management programmes can be successful however, it is noteworthy, that they are all characterised by partnerships between state governments and donors, such as the World Bank. This is thought to be significant as the additional funds brought in by the donor has enabled greater attention to capacity building, particularly among engineers and bureaucrats, as well as specialist knowledge about community management programme management.

Table 1 - Coverage of the successful community management state programmes As shown in Table 2 below, beyond the five large-scale programmes, the remaining small-scale programmes vary in size. Many of the reported micro to medium-scale programmes are NGO initiatives and whilst they are important in their own right, the state-wide programmes dwarf these in terms of the number of villages served and 
demonstrate the value of working with government, even if initiating change in such environments is a difficult process.

Table 2 - Small and medium successful community management programmes

As a management model, community management can be applied in different types of water initiatives covering different technologies or areas of focus. As shown in Table 3 across the sample, the majority focused on piped water supply or mixed (piped water supply and handpumps) reflecting the current priorities of government. Surprisingly, given the perceived association that many in the sector make between community management and handpumps, only a minority were found to focus on 'handpump' schemes. Beyond these categories there was variety, with some cases focusing on 'source conservation' and some others on 'reverse osmosis' plants. There were also six cases that focused on 'management' case studies however there was no useful data on the number of villages being addressed in these case studies.

Table 3 - Successful community management programmes by area of focus

Making an assessment of community management into the typologies discussed above, we found that 68 out of 92 cases contained enough information to classify the case studies into the typologies. Four of the larger scale programmes were classified in each typology as the exact institutional arrangements appeared to vary across the programmes. This follows the pattern reported by Rout (2014) in her analysis of the demand-responsive approach in Odisha, which found both a form of direct provision and community management in the same programme. Beyond these multi-classified programmes, around one quarter of the cases were characterised by the Direct Provision 
with Community Involvement. Direct Provision by the Gram Panchayat is extremely common in India and is expected to account for many more programmes across the country than reported here. The ones included here are those which have a dedicated community engagement initiative alongside the direct provision and which were identified in our initial review. The distinction between the decentralised direct provision by the Gram Panchayat, that in its pure form is not a form of community management, and a model where the Gram Panchayat remains the service provider but is actively supported by a community body, such as a water committee, is where we consider the line to be between community management and government provision. Beyond direct provision, over sixty percent of the programmes were classified as Community Management Plus. This form of community management reflects the traits most commonly articulated to describe the model, with a community entity taking the role of service provider with support from other entities. Finally, the most advanced form - Professional Community Based Management - was common in around 14 percent of the cases. The development of these mini-utility type operations governed by community institutions is expected to grow when (and if) the proceeds from India's economic growth spreads into the rural areas, especially in areas close to urban centres. The snapshot provided in Figure 2 gives our best estimate at the current state of play in India but we expect this is likely to change. In fact, we content that it must change as India develops if community management is to remain an integral part of its water policy.

Figure 2 - Community Management in India by typology

\section{Conclusion}

Community management is a long established phenomenon in the rural drinking water supply sector that has been the subject of critical discussion for a number of years. Yet 
the model continues to play a fundamental role in the provision of water services for hundreds of millions of people around the world. At this time of change in the policy ambitions of governments and donors, it remains imperative to continue to engage with community management conceptually to further collective understanding about how it actually functions as the sector changes. In this regard, with an emphasis on India, the paper has argued that there is no single community management model but rather a loose and overlapping collection of models with varying degrees of community involvement and external support. Identifying the role of an enabling support environment as essential to the viability of community management in supporting increasing complex technical systems, such as multi-village piped water supply, the paper makes the interface between community contribution and this enabling support environment as the basis for a new conceptual model that takes better account of these differences. This is important as it shifts the balance of responsibility for operation and maintenance away from rural communities who have for too long been over burdened with the expectation that they should be independently successful 'public service managers'. Instead, external bodies, particularly government bodies, but in certain situations this may also be NGOs or other agencies, need to recognise that they must play a role monitoring performance and as a continuous source of support. However, as one can expect, there is no one size fits all approach and so understanding that communities will need different types of support, which will likely be relational to their own internal carrying capacity, governments are in a better position to successful take up the role of a successful support entity if they can better differentiate the types of support needed in different situations.

For this purpose, the paper has outlined three broad models of community management, including one in which the external agency must take responsibility for much of the 
operation and maintenance of the system. This form of direct provision with community involvement does, however, engage the community as overseers of the service with them making key decisions with regards to issues such as technology choice and tariff level. Community management plus is another category, with this reflecting the most typical understanding of the model, with the community establishing a largely voluntary body for the operation and minor maintenance of schemes, but with the external agencies playing a role as a proactive monitoring agency ready to provide support both in a supply-driven and demand-driven manner. Finally, the Professional Community Based Management model involves usually richer communities reducing the 'volunteerism' role they had been assumed to play in their water supply, but instead opting for higher levels of contributions either directly through tariffs or, on a societal level, through contribution of higher levels of tax revenue toward water supply. In India, our review of 92 successful community management programmes lead to the classification that one quarter are reflective of a form of direct provision with community involvement, whilst over $60 \%$ can be characterised as a 'classic' form of community management with direct support, and nearly $15 \%$ in the professional community management category. We expect there is likely to be a crude trend toward the professional model as India increases its wealth and that it is prudent for government to help support this transition wherever possible. Going forward a number of research questions emerge regarding the resource implications of this various models both at the community level and the support level. There are also questions regarding the desirability of the different models to various stakeholders, not least rural communities themselves. 


\section{References}

Bakalian, A., \& Wakeman, W. (2009). Post-construction support and sustainability in community-managed rural water supply: case studies in Peru, Bolivia and Ghana. (No. 14). Washington D.C.: WSP.

Baumann, E. (2006). Do operation and maintenance pay? Waterlines, 25(1), 10-12.

Black, M., \& Talbot, R. (2004). Water: a matter of life and health. New Delhi: Oxford University Press.

Bolt, E., \& Fonseca, C. (2001). Keep It Working: a field manual to support community management of rural water supply. The Hague: IRC.

Census of India. (2011). Main Source of Drinking Water 2001-2011. New Delhi: Government of India.

Colin, J. (1999). VLOM for Rural Water Supply: Lessons from Experience (No. Task No: 162). Loughborough, UK: WEDC.

Davis, J., \& Iyer, P. (2002). Taking Sustainable Rural Water Supply Services to Scale. A Discussion Paper. Washington D.C.: WSP.

Dayal, R., Wijk-Sijbesma, C. A., \& Mukherjee, N. (2000). Methodology for participatory assessments : with communities, institutions and policy makers : linking sustainability with demand, gender and poverty: METGUIDE. Washington D.C.: WSP.

Deverill, P., Bibby, S., Wedgwood, A., \& Smout, I. (2002). Designing water supply and sanitation projects to meet demand in rural and peri-urban communities - Book 1: Concept, principles and practice. Loughborough, UK: WEDC.

DWSD-GoJ. (2015). Programmes. Government of Jharkhand. Retrieved May 7, 2015, from http://112.133.209.136:8000/dwsd/webpages/Programme.aspx

Franceys, R., \& Gerlach, E. (2008). water and sanitation for the poor: Economic regulation for public and private partnerships. London: Earthscan.

Government of India. (2003). Swajaldhara. New Delhi: Government of India.

Government of India. (2009). Report of Rajiv Gandhi National Rural Drinking Water Mission. New Delhi: Government of India.

Government of India. (2011). Census data: preliminary results. New Delhi: Government of India.

Government of India. (2012). A handbook for Gram Panchayats - to help them plan, implement, operate, maintain and manage drinking water security. New Delhi: Government of India.

Government of India. (2015). Government Constitutes National Institution for Transforming India (NITI) Aayog. New Delhi: Government of India. Retrieved May 10, 2015, from http://pib.nic.in/newsite/PrintRelease.aspx?relid=114268

Harvey, P. A., \& Reed, R. A. (2006). Community-managed water supplies in Africa: sustainable or dispensable? Community Development Journal, 42(3), 365-378. http://doi.org/10.1093/cdj/bs1001

Hutchings, P., Chan, M. Y., Cuadrado, L., Ezbakhe, F., Mesa, B., Tamekawa, C., \& 
Franceys, R. (2015). A systematic review of success factors in the community management of rural water supplies over the past 30 years. Water Policy, 17(5), 963. http://doi.org/10.2166/wp.2015.128

Isham, J., \& Kahkonen, S. (2002). Institutional Determinants of the Impact of Community-Based Water Services: Evidence from Sri Lanka and India. Economic Development and Cultural Change, 50(3), 667-691. http://doi.org/10.1086/342357

James, A. J. (2004). India's Sector Reform Projects and Swajaldhara Programme A Case of Scaling up Community Managed Water Supply. The Hague, Netherlands: IRC.

James, A. J. (2011). Supporting Rural Water Supply: Assessing Progress Towards Sustainable Service Delivery (India). The Hague, Netherlands: IRC.

Jones, S. (2013). How can INGOs help promote sustainable rural water services? An analysis of wateraid's approach to supporting local governments in mali. Water Alternatives, 6(3), 350-366. Retrieved from http://www.scopus.com/inward/record.url?eid=2-s2.084886887823\&partnerID=tZOtx3y1

Lammerink, M., \& de Jong, D. (1999). Community water management. London: IIED.

Lockwood, H. (2002). Institutional Support Mechanisms for Community-managed Rural Water Supply and Sanitation Systems in Latin America. Washington D.C.: WSP.

Lockwood, H., Bakalian, A., \& Wakeman, W. (2003). essing sustainability in rural water supply: the role of follow-up support to communities; Literature review and desk review of rural water supply and sanitation project documents. Washington, DC.: WSP.

Lockwood, H., \& Le Gouais, A. (2011). Professionalising community-based management for rural water services. Building block briefing note. The Hague, Netherlands: IRC.

Lockwood, H., \& Smits, S. (2011). Supporting Rural Water Supply: Moving Towards a Service Delivery Approach. Warwickshire, UK.: Practical Action Publishing Ltd.

Marks, S. J., \& Davis, J. (2012). Does User Participation Lead to Sense of Ownership for Rural Water Systems? Evidence from Kenya. World Development, 40(8), 1569-1576. http://doi.org/10.1016/j.worlddev.2012.03.011

McCommon, C., Warner, D., \& Yohalem, D. (1990). Community Management of Rural Water Supply and Sanitation Services: WASH Technical Report 67. Washington D.C.: USAID.

Ministry of Drinking Water and Sanitation (MDWS). (2013). National Rural Drinking Water Programme, Rajiv Gandhi Drinking Water Mission, Movement towards ensuring people's Drinking Water Security in Rural India, Framework for Implementation (updated 2013). New Delhi: Ministry of Drinking Water and Sanitation.

Moriarty, P., Smits, S., Butterworth, J., \& Franceys, R. (2013). Trends in rural water supply: Towards a service delivery approach. Water Alternatives, 6(3), 329-349. Retrieved from http://www.scopus.com/inward/record.url?eid=2-s2.0- 
84886886391\&partnerID=tZOtx3y1

Paul, S. (1987). Community Participation in Development Projects: The World Bank Experience. In Readings in Community Participation. Washington DC: EDI.

Rout, S. (2014). Institutional variations in practice of demand responsive approach: evidence from rural water supply in India. Water Policy, 16(4), 650. http://doi.org/10.2166/wp.2014.155

Schouten, T., \& Moriarty, P. (2003). Community Water, Community Management. From System to Service in Rural Areas. London: ITDG Publishing.

Smits, S., Franceys, R., Mekala, S., \& Hutchings, P. (2015). Understanding the resource implications of the "plus" in community management of rural water supply systems in India: concepts and research methodology (No. 1). Cranfield: Community Water Plus.

Smits, S., Rojas, J., \& Tamayo, P. (2013). The Impact of Support to Community-Based Rural Water Service Providers: Evidence from Colombia. Water Alternatives. 6(3), 384-404.

Smits, S., Verhoeven, J., Moriarty, P., Fonseca, C., \& Lockwood, H. (2011). Arrangements and costs of support to rural water service providers (No. 5). WASHCost. The Hague, Netherlands: IRC.

Srivastava, S. (2012). Swajaldhara: ?Reversed? Realities in Rural Water Supply in India. IDS Bulletin, 43(2), 37-43. http://doi.org/10.1111/j.17595436.2012.00305.x

Stern, P., Townsend, D., \& Stephens, R. (2007). Telecommunications Universal Access Programs in Latin America. Bogotá, Colombia: Latin American Forum of Telecommunications Regulators (Regulatel).

Whittington, D., Davis, J., Prokopy, L., Komives, K., Thorsten, R., Lukacs, H., ... Wakeman, W. (2009). How well is the demand-driven, community management model for rural water supply systems doing? Evidence from Bolivia, Peru and Ghana. Water Policy, 11(6), 696-718. http://doi.org/10.2166/wp.2009.310

Water and Sanitation Program (WSP). (2002). Discussion Paper \#1 Sustainability of Rural Water Supply Projects: Lessons from the Past - South Asia Region. Washington D.C: WSP. 
Table 1. Coverage of the successful community management state programmes (Calculated from Community Water Plus sampling frame; available in supplementary information)

\begin{tabular}{lll}
\hline Programme & State & Villages served \\
\hline Water and Sanitation Management & Gujarat & 18,185 \\
Organisation (WASMO) & & \\
Jalswarajya & Maharashtra & 3,749 \\
Jalanidhi & Kerala & 3,715 \\
Jal Nirmal & Karnataka & 2,292 \\
\hline
\end{tabular}


Table 2 - Small and medium successful community management schemes (Calculated from Community Water Plus sampling frame; available in supplementary information)

\begin{tabular}{llll}
\hline Category & Number of villages & $\begin{array}{l}\text { Total number of } \\
\text { schemes }\end{array}$ & $\begin{array}{l}\text { Total number of } \\
\text { villages served }\end{array}$ \\
\hline Single & 1 & 23 & 23 \\
Micro & $2-9$ & 7 & 32 \\
Small-scale & $10-20$ & 6 & 90 \\
Intermediate & $21-100$ & 13 & 795 \\
Medium & $100-1,000$ & 10 & 3,065 \\
\hline
\end{tabular}


Table 3 - Successful community management schemes by area of focus (Calculated from Community Water Plus sampling frame; available in supplementary information)

\begin{tabular}{lll}
\hline Area of focus & $\begin{array}{l}\text { Total number of } \\
\text { schemes }\end{array}$ & $\begin{array}{l}\text { Total number of } \\
\text { villages served }\end{array}$ \\
\hline Piped water supply & 58 & 20,203 \\
Handpumps & 7 & 158 \\
Mixed (piped water supply and handpumps) & 4 & 12,316 \\
Reverse Osmosis & 3 & 201 \\
Source conservation & 16 & 533 \\
\hline
\end{tabular}


List of Figure Titles (files attached separately as TIFFs)

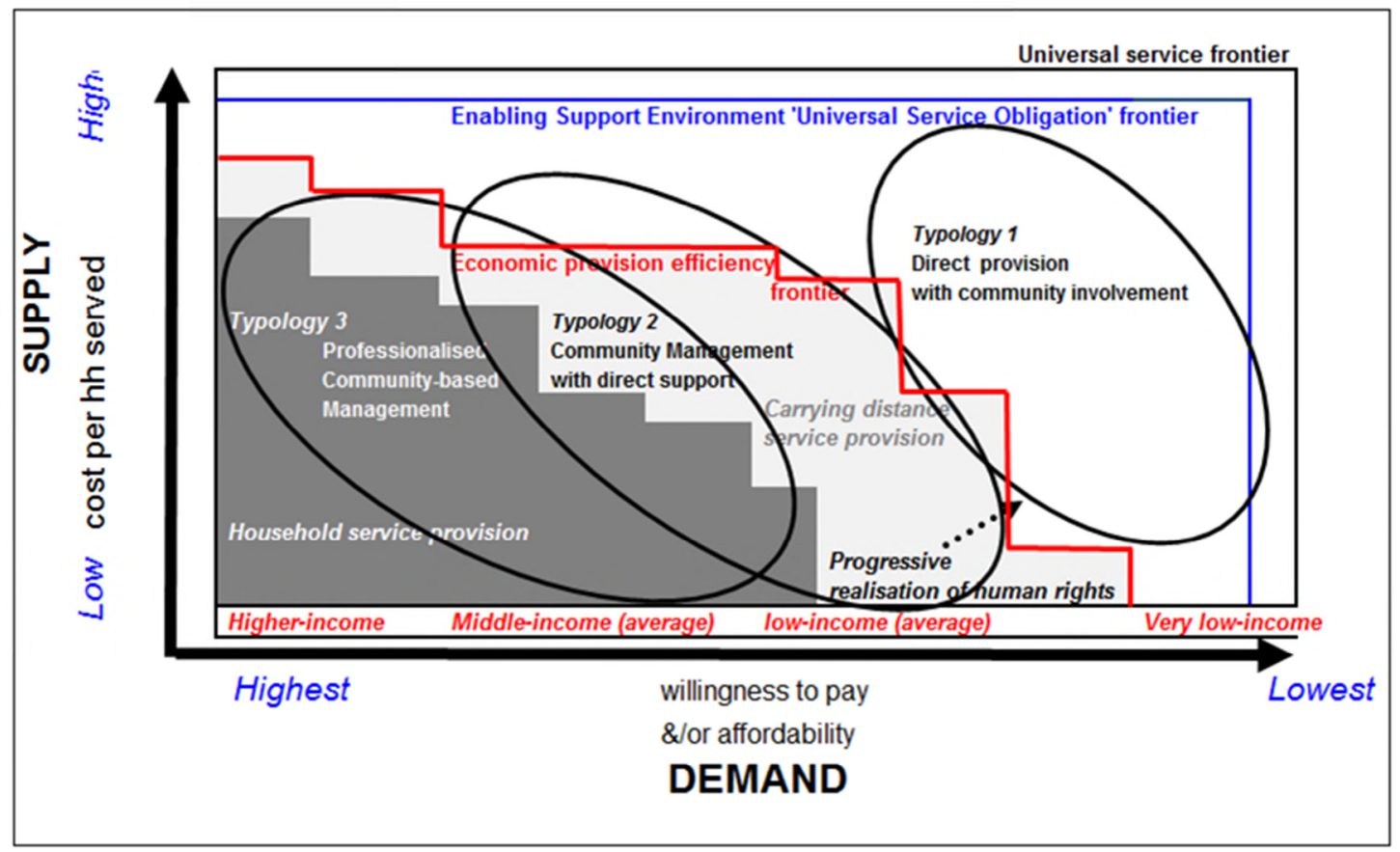

Figure 1: Typologies of Community Management in relation to demand and costs of water supplies. Source: adapted from Franceys and Gerlach (2008) after Stern et al. (2007)

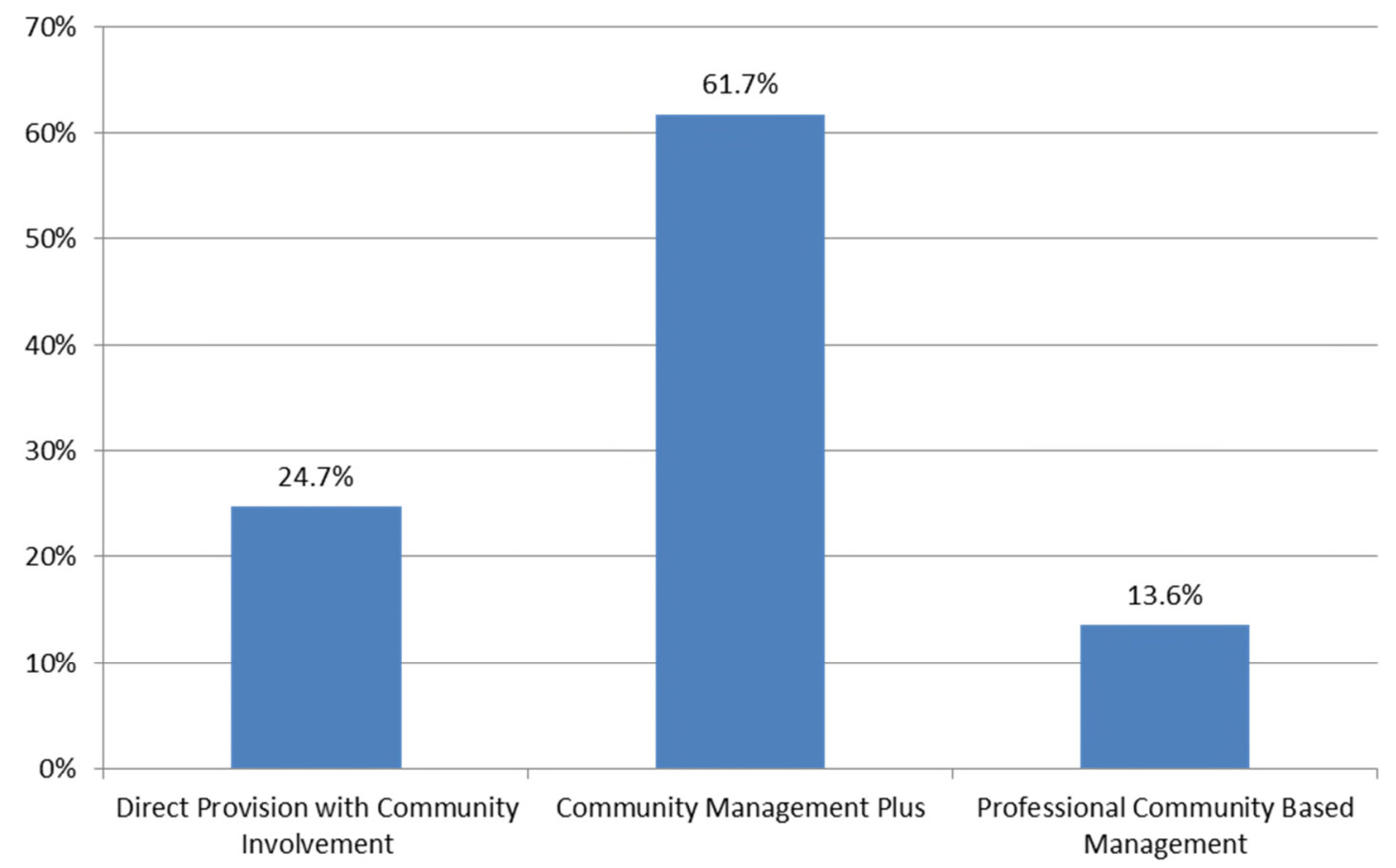


Figure 2 - Community Management in India by typology (Calculated from Community Water Plus sampling frame; available in supplementary information) 